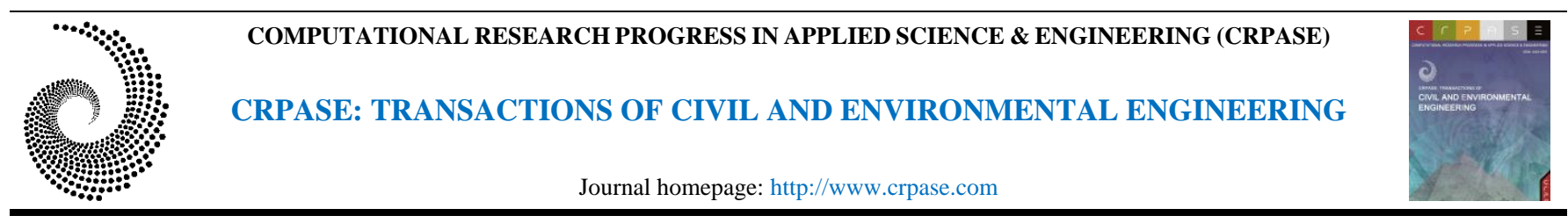

CRPASE: Transactions of Civil and Environmental Engineering 8 Article ID: 2223, 1-6, Special Issue: NCTT 2021

ISSN 2423-4591

Research Article

\title{
Modeling of Pedestrian Flow Density in Signalized Intersections Using Fuzzy Method (Case Study: Rasht City)
}

Amin Alizadeh Tajan*, Mahmoud Ameri, Barat Mojaradi

School of Civil engineering, Iran University of Science and Technology (IUST), Tehran, Iran

\begin{tabular}{ll}
\hline Keywords & Abstract \\
\cline { 2 - 3 } $\begin{array}{l}\text { Pedestrian, } \\
\text { Signalized intersections, }\end{array}$ & $\begin{array}{l}\text { Signalized intersections are among the facilities where pedestrians may have collisions with } \\
\text { Crosswalk, }\end{array}$ \\
$\begin{array}{l}\text { in network capacity. For this reason, recognizing the behavioral characteristics of } \\
\text { pensity, }\end{array}$ & $\begin{array}{l}\text { pedestrians is the most important element in designing intersections and pedestrian facilities. } \\
\text { Fuzzy model. }\end{array}$ \\
Therefore, by investigating two signalized intersections in Rasht city, Iran, data of 8277 \\
pedestrians were collected and then the flow of pedestrians was modeled using fuzzy \\
method. The results showed that the crosswalk crossing conditions by moving a higher flow \\
rate compared to non-crossing areas are more suitable and desirable for pedestrians. The \\
results also indicated that in the conditions of crossing from crosswalks and unauthorized \\
areas, the superior models have $\mathrm{R}^{2}$ of $80.88 \%$ and $90.68 \%$, respectively, and the input and \\
output membership function algorithm was Gaussian which has 4 membership functions for \\
each of the inputs to predict the density values in the total intersections.
\end{tabular}

\section{Introduction}

Walking is one of the modes of transportation that depends on personal effort, which mainly has two purposes of recreation and transportation or a combination of both $[1,2]$. Today, the study of the behavior and flow of pedestrians is inevitable due to the growing interest in the issue of sustainable transportation, of which walking is one of the basic parts. Topics such as emergency evacuation of pedestrians, design and access to public transportation stations, design of sidewalks and crosswalks, and design of intersections and traffic lights in areas where vehicles collide with pedestrians are among the topics that make the study of pedestrian behavior and traffic inevitable [3-5].

Pedestrians usually have more complex behaviors than vehicle drivers due to personal characteristics such as gender, age, number of group members, type of clothing, fewer legal restrictions, and greater freedom in movement and route choice $[6,7]$. Also, pedestrian decision-making is complex and influenced by various factors, so modeling pedestrian behavior has always faced serious challenges $[8$, 9].

One of the main factors influencing the crossing of pedestrians due to traffic and safety conditions and considerations is signalized and unsignalized intersections. In these areas, pedestrians have a key role because they may disrupt the movement of vehicles even in spite of low traffic. These facilities are among the places where users of different roads have significant interactions with each other, which can lead to severe injuries to pedestrians $[10,11]$. Intersections as traffic junctions are one of the important factors determining the capacity of the network and any disruption in it causes a severe reduction in network capacity [12]. For this reason, recognizing the behavior of pedestrians in different situations and guiding them to appropriate routes by considering the least collision between pedestrians and

* Corresponding Author: Amin Alizadeh Tajan

E-mail address: amin_az7@outlook.com

Received: 14 November 2021; Revised: 11 December 2021; Accepted: 10 January 2022

https://doi.org/ 10.52547/crpase.8.2223

Academic Editor: Mahdi Feizbahr

Please cite this article as: A. Alizadeh Tajan, M. Ameri, B. Mojaradi, Modeling of Pedestrian Flow Density in Signalized Intersections Using Fuzzy Method (Case Study: Rasht City), Computational Research Progress in Applied Science \& Engineering, CRPASE: Transactions of Civil and Environmental Engineering 8 (2022) 1-6, Article ID: 2223. 
other vehicles is one of the most important issues that should be addressed in the design of intersections and pedestrian facilities.

In this study, by examining the pedestrian flow for crossing and non-crossing areas, the pedestrian flow modeling is conducted by fuzzy logic method.

\section{Literature Review}

In recent years, many researchers have examined the speed of pedestrians. Pedestrian speed is one of the essential and measurable parameters that plays a key role in scheduling traffic lights at intersections and constructing facilities such as sidewalks, crosswalks and islands. Transportation planners also use pedestrian speed to formulate their policies. Among the factors affecting the speed of walking can be the personal characteristics of pedestrians (age, gender, and weight), purpose of travel (work, recreation, educational), weather conditions and characteristics of walking facilities (slope, pavement, attractiveness of the route) [13].

Twarogowska et al. (2014) in a study entitled a comparative study of macroscopic pedestrian models compared the capability of the proposed models based on features such as travel time minimization, avoidance of crowded areas, and complex movements such as stopmovement wave and bottleneck obstruction [14].

In a study entitled analysis of interrelationship between pedestrian flow parameters using artificial neural network, Doss et al. (2015) evaluated flow parameters using the Greenshield, Underwood, and neural network methods. They showed that the neural network model performed better in predicting the flow parameters that the mean absolute error (MAE) and root mean square error (RMSE) values for the superior neural network model were much lower than the corresponding values for the other models [15].

Chai et al. (2016) in a research entitled fuzzy logicbased observation and evaluation of pedestrians' behavioral patterns by age and gender concluded that age and gender have a significant effect on pedestrian behavior patterns. They also found that, both groups of older and younger pedestrians were less prone to high-risk behaviors than adult pedestrians, and males had higher cognition skills than females in critical and dangerous situations [16].

To simulate pedestrian movements, Song et al. (2018) used a four-layer neural network to train multiple scenarios by normalizing pedestrian-related states, changing the speed vector to scalar, and using more information to plan the route. The results indicated that the neural network could be applied to several pedestrian scenarios, including evacuation, and also provided a more realistic speed-density curve and less path fluctuation [17].

Yang et al. (2020) used the fuzzy logic method to evaluate which route could be suitable for guiding pedestrians to evacuate, in which the normalized distance from the output and the normalized density around the output were identified as input variables of the fuzzy inference system. The simulation results showed that the evacuation efficiency is closely related to the building view and the amount of guidance and exit width, so that more guidance, more view and wider output can lead to safe evacuation of more pedestrians [18].

\section{Methodology}

\subsection{Data Collection}

In this study, two important and crowded signalized intersections in Rasht city, Iran, were selected. Then, using video recording, data were collected for pedestrians passing through the crossing and non-crossing areas. The method of calculating the speed in this study was that the walking time of pedestrians is measured between two specific points and with a certain distance, and the speed is calculated by dividing the distance by the measured walking time. Also, the flow rate was measured by counting the number of pedestrians between two points in one minute, and the density of pedestrians was calculated according to the relation $\mathrm{V}=\mathrm{S} \times \mathrm{D}$ based on Highway Capacity Manual (HCM) [19].

\subsection{Fuzzy Method}

After collecting 8277 pedestrian data, pedestrian flow modeling with a macroscopic approach was performed using fuzzy logic method. Today, fuzzy logic, as an alternative to classical mathematics, is a powerful mathematical tool in various sciences that reduces the complexity of the mathematical relationships in models. Most human information can not be classified into two groups, for example, it is not possible to classify parameters such as pressure, temperature, size and the like in two groups of zero and one. To describe such parameters, a degree is assigned to them. This idea is based on fuzzy sets rather than classical logic. In the classical set, an object belongs to the set or not, but in the fuzzy set, degrees of membership for a set are introduced. A fuzzy set has a membership function in which different degrees of membership are defined for specific elements. The membership function is defined as discrete values or by curves.

\section{Results}

Table Tables 1-2 show that the optimal combination for the fuzzy model in terms of crossing from and out of the crosswalk according to the model evaluation criteria, had a Gaussian input and output function algorithm and 4 membership functions for each of the inputs which had the lowest RMSE and the highest $\mathrm{R}^{2}$ and model efficiency. 
Table 1. Statistical results of fuzzy model in crossing from the crosswalk

\begin{tabular}{ccccccccc}
\hline $\begin{array}{c}\text { Number of } \\
\text { membership } \\
\text { functions }\end{array}$ & $\begin{array}{c}\text { Algorithm of } \\
\text { input } \\
\text { membership } \\
\text { functions }\end{array}$ & $\begin{array}{c}\text { Algorithm of } \\
\text { output } \\
\text { membership } \\
\text { functions }\end{array}$ & $\begin{array}{c}\text { RMSE } \\
\text { (train) }\end{array}$ & $\begin{array}{c}\text { Efficiency } \\
\text { of train } \\
\text { data }\end{array}$ & $\begin{array}{c}\text { RMSE } \\
\text { (test) }\end{array}$ & $\begin{array}{c}\text { Efficiency } \\
\text { of test data }\end{array}$ & $\mathrm{R}^{2}$ (train) & $\mathrm{R}^{2}$ (test) \\
\hline$[22]$ & gaussmf & gaussmf & 0.1136 & -1.2 & 0.1174 & -0.72 & 92.40 & 93.71 \\
\hline$[23]$ & gaussmf & gaussmf & 0.1196 & -1.43 & 0.1364 & -1.33 & 62.31 & 65.70 \\
\hline$[34]$ & gaussmf & gaussmf & 0.2173 & -7.05 & 0.2308 & -5.68 & 75.57 & 82.05 \\
\hline$[44]$ & gaussmf & gaussmf & $\mathbf{0 . 0 5 1 9}$ & $\mathbf{0 . 5 4}$ & $\mathbf{0 . 0 5 9 9}$ & $\mathbf{0 . 5 4}$ & $\mathbf{8 0 . 1 2}$ & $\mathbf{7 7 . 7 0}$ \\
\hline$[24]$ & gaussmf & gaussmf & 0.1584 & -3.28 & 0.1596 & -2.19 & 83.16 & 90.95 \\
\hline$[22]$ & trimf & trimf & 0.1475 & -2.7 & 0.1494 & -1.79 & 90.03 & 91.89 \\
\hline$[23]$ & trimf & trimf & 0.1325 & -2 & 0.1429 & -1.55 & 92.62 & 93.83 \\
\hline$[34]$ & trimf & trimf & 0.1613 & -3.43 & 0.1723 & -2.72 & 74.60 & 80.25 \\
\hline$[44]$ & trimf & trimf & 0.0637 & 0.3 & 0.072 & 0.34 & 78.23 & 75.66 \\
\hline$[24]$ & trimf & trimf & 0.1273 & -1.76 & 0.1387 & -1.41 & 84.96 & 89.19 \\
\hline
\end{tabular}

Table 2. Statistical results of fuzzy model in crossing out of the crosswalk

\begin{tabular}{|c|c|c|c|c|c|c|c|c|}
\hline $\begin{array}{l}\text { Number of } \\
\text { membership } \\
\text { functions }\end{array}$ & $\begin{array}{l}\text { Algorithm of } \\
\text { input } \\
\text { membership } \\
\text { functions }\end{array}$ & $\begin{array}{l}\text { Algorithm of } \\
\text { output } \\
\text { membership } \\
\text { functions }\end{array}$ & $\begin{array}{l}\text { RMSE } \\
\text { (train) }\end{array}$ & $\begin{array}{c}\text { Efficiency } \\
\text { of train } \\
\text { data }\end{array}$ & $\begin{array}{l}\text { RMSE } \\
\text { (test) }\end{array}$ & $\begin{array}{l}\text { Efficiency } \\
\text { of test data }\end{array}$ & $\mathrm{R}^{2}$ (train) & $\mathrm{R}^{2}$ (test) \\
\hline [22] & gaussmf & gaussmf & 0.0488 & -0.22 & 0.0586 & -0.24 & 90.47 & 90.21 \\
\hline [23] & gaussmf & gaussmf & 0.0581 & -0.73 & 0.0501 & 0.09 & 70.03 & 57.61 \\
\hline [34] & gaussmf & gaussmf & 0.0773 & -2.06 & 0.0712 & -0.83 & 80.96 & 75.21 \\
\hline [44] & gaussmf & gaussmf & 0.0227 & 0.73 & 0.0176 & 0.88 & 86.90 & 95.40 \\
\hline [24] & gaussmf & gaussmf & 0.0731 & -1.73 & 0.0722 & -0.88 & 84 & 81.62 \\
\hline$[22]$ & trimf & trimf & 0.0654 & -1.19 & 0.078 & -1.2 & 87.60 & 89.40 \\
\hline$[23]$ & trimf & trimf & 0.0595 & -0.81 & 0.0739 & -0.97 & 89.60 & 90.54 \\
\hline [34] & trimf & trimf & 0.0273 & 0.61 & 0.029 & 0.69 & 86.30 & 84.22 \\
\hline [44] & trimf & trimf & 0.0352 & 0.36 & 0.0289 & 0.69 & 80.12 & 85.64 \\
\hline [24] & trimf & trimf & 0.0574 & -0.69 & 0.065 & -0.52 & 89.34 & 85.93 \\
\hline
\end{tabular}

Figures 1-4 show the appropriate correlation of the model output with the target data, density, which indicates a low error rate. Figures 5-6 also show the optimal fuzzy model regression results for crossing from and out of the crosswalk.
Figure 7 also shows the relationship between flow rate, speed and density in terms of crossing from and out of the crosswalk in the form of three-dimensional diagrams.
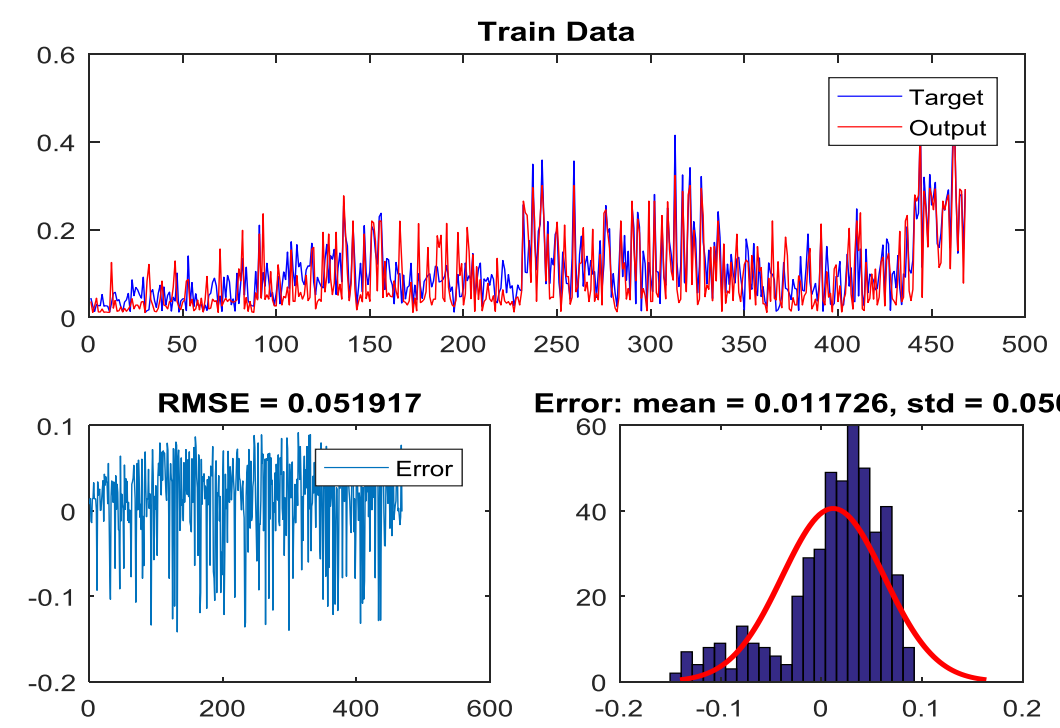

Figure 1. Comparison of actual and predicted values for crossing from the crosswalk for train data 

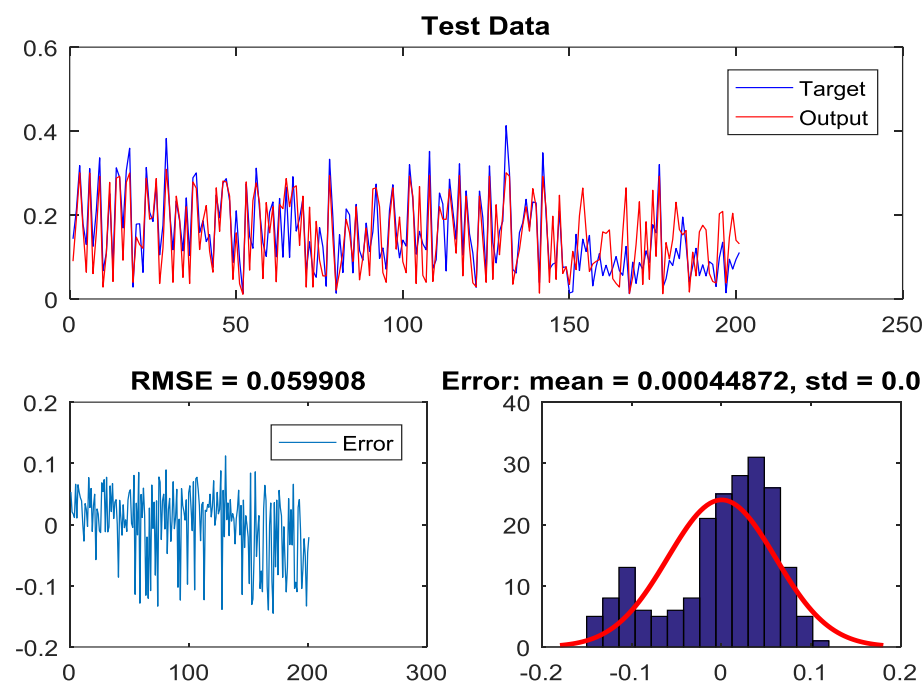

Figure 2. Comparison of actual and predicted values for crossing from the crosswalk for test data
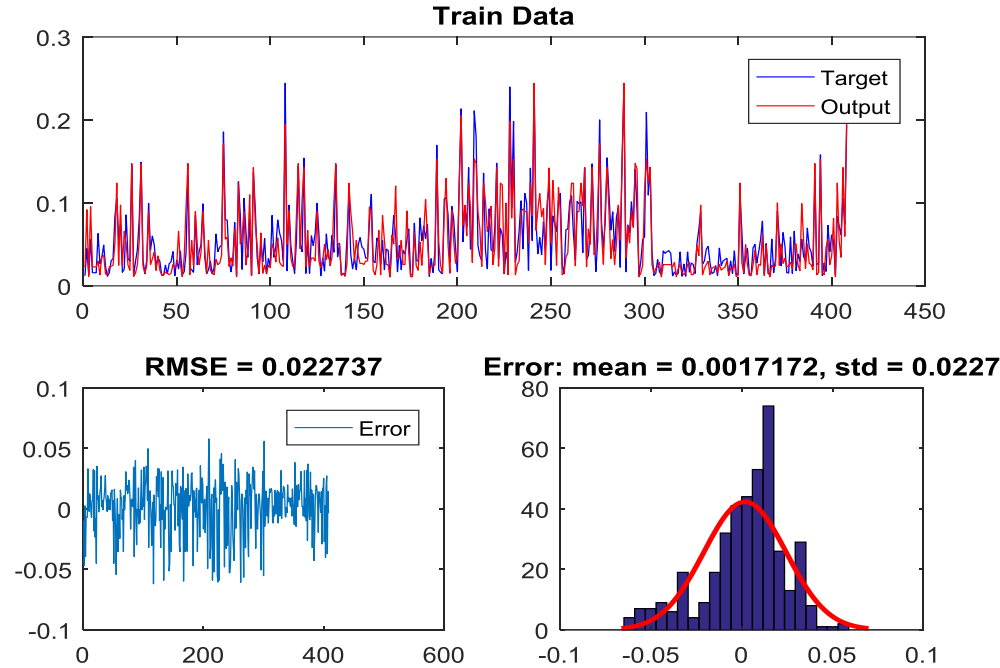

Figure 3. Comparison of actual and predicted values for crossing out of the crosswalk for train data
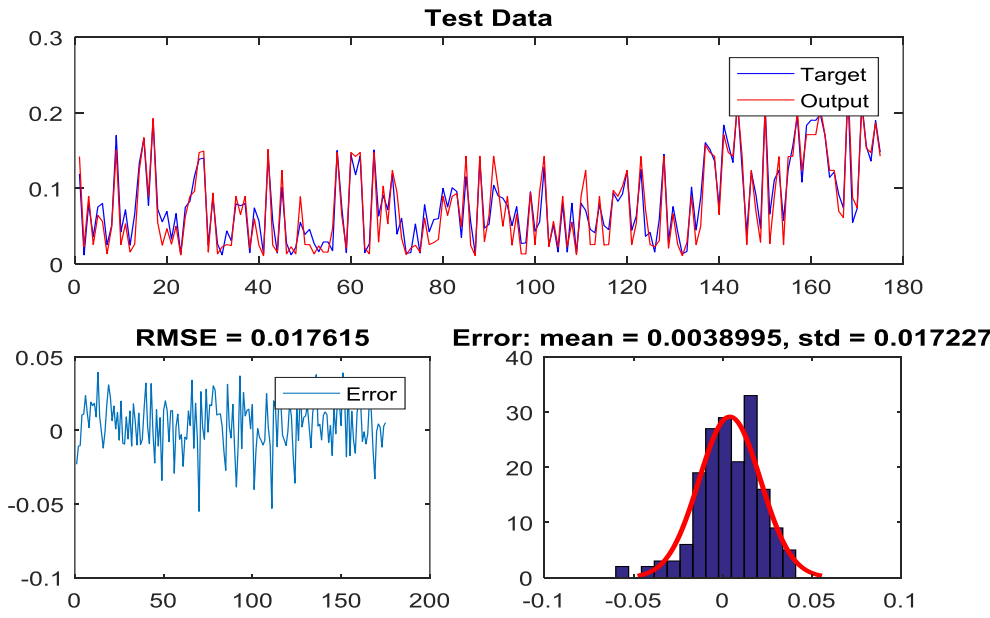

Figure 4. Comparison of actual and predicted values for crossing out of the crosswalk for test data

By comparing these two conditions, it can be seen that the conditions of crossing from the crosswalk are more suitable for pedestrians because although the crossing conditions have a higher flow rate, the density is 0.35 , which has a long distance from the critical density (0.8-1). 

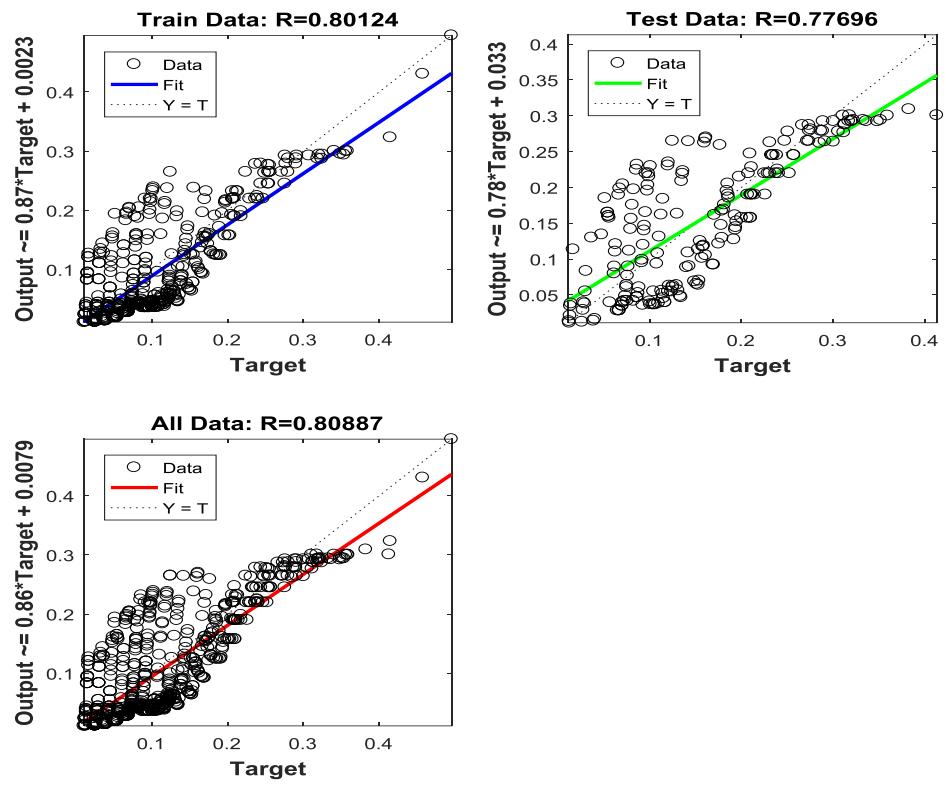

Figure 5. Fuzzy model regression results for crossing from the crosswalk
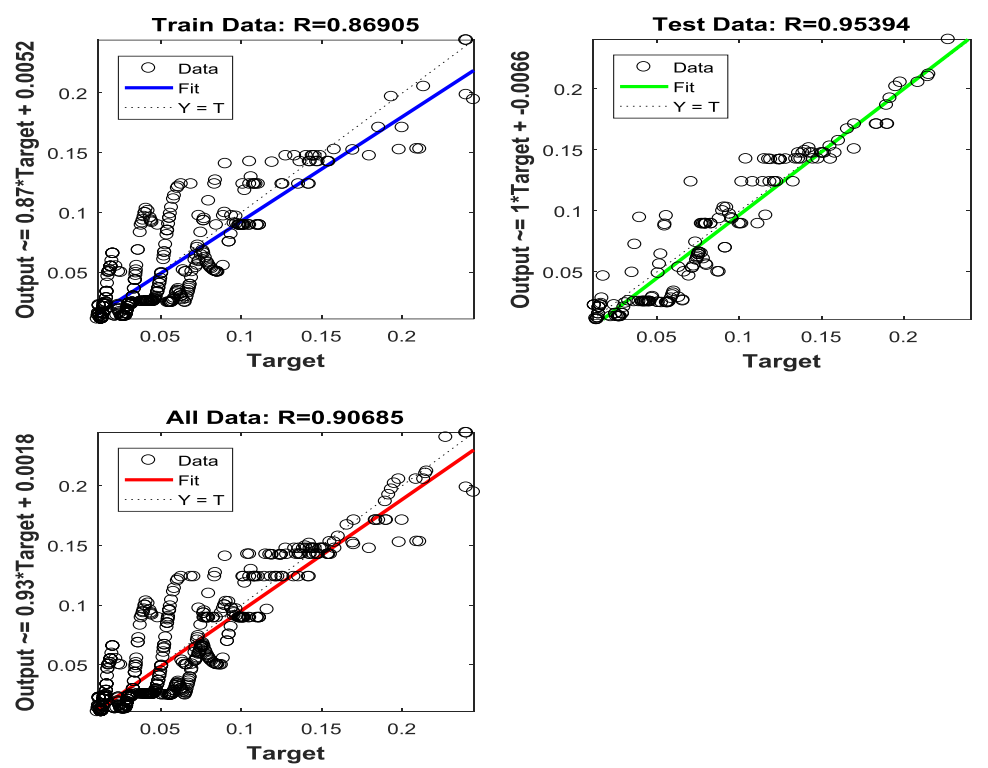

Figure 6. Fuzzy model regression results for crossing out of the crosswalk

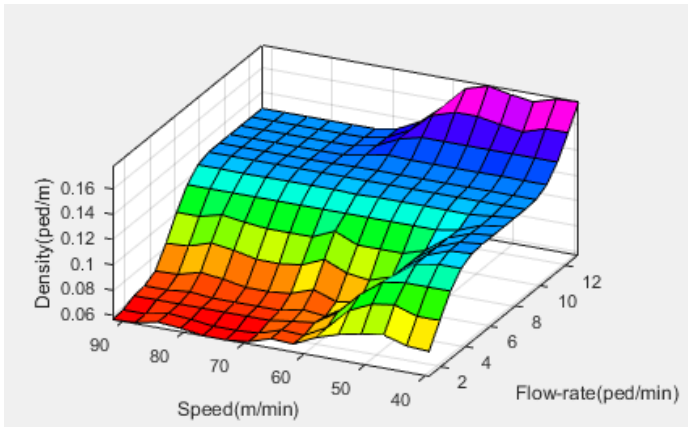

(a)

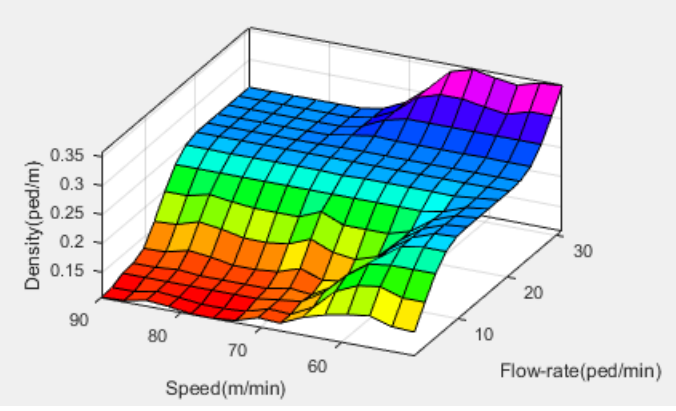

(b)

Figure 7. Fuzzy model regression results for: a) crossing out of the crosswalk b) crossing from the crosswalk 


\section{Conclusion}

The aim of this study was to model the density of pedestrians at signalized intersections. The following results are obtained:

- In these facilities, the conditions of crossing from the crosswalk indicate a higher flow rate than the non-crossing areas, showing that the crosswalk crossing conditions are more available and more desirable for pedestrians.

- In case of crossing from the crosswalk, the superior model has $\mathrm{R}^{2}$ of $80.88 \%$ and the algorithm has a Gaussian input and output membership function and 4 membership functions for each of the inputs.

- In case of crossing out of the crosswalk, the superior model has $\mathrm{R}^{2}$ of $90.68 \%$ and the algorithm has a Gaussian input and output membership function and 4 membership functions for each of the inputs.

- For future research, other machine learning techniques [20-24] and optimization algorithms [25-28] can be incorporated into the proposed approaches to obtain more accurate results.

\section{Reference}

[1] S. M. Hosseinian, V. Najafi Moghaddam Gilani, B. Mirbaha, A. Abdi Kordani, Statistical Analysis for Study of the Effect of Dark Clothing Color of Female Pedestrians on the Severity of Accident Using Machine Learning Methods. Mathematical Problems in Engineering 2021 (2021).

[2] H. L. Kluepfel, A cellular automaton model for crowd movement and egress simulation, 2012.

[3] H. Behbahani, V. N. M. Gilani, A. Amini, N. Kamboozia, S. Hosseinian, Fuzzy-neural analysis of pedestrian flow crossing urban intersections. In: Proceedings of the 18th International Conference on Traffic \& Transportation Engineering, (2020).

[4] S. M. Hosseinian, V. N. M. Gilani, Analysis of factors affecting urban road accidents in rasht metropolis. Eng Transactions 1 (2020) $1-4$.

[5] C. Gruden, I. I. Otković, M. Šraml, Pedestrian safety at roundabouts: a comparison of the behavior in Italy and Slovenia. Transportation Research Procedia 60 (2022) 528-535.

[6] S. Marisamynathan, P. Vedagiri, Modeling pedestrian crossing behavior and safety at signalized intersections. Transportation research record 2672 (2018) 76-86.

[7] X. Zhuang, C. Wu, Pedestrians' crossing behaviors and safety at unmarked roadway in China. Accident analysis \& prevention 43 (2011) 1927-1936.

[8] S. Yi, H. Li, X. Wang, Pedestrian behavior understanding and prediction with deep neural networks. In: European Conference on Computer Vision, Springer (2016) 263-279.

[9] D. Ridel, E. Rehder, M. Lauer, C. Stiller, D. Wolf, A literature review on the prediction of pedestrian behavior in urban scenarios. In: 2018 21st International Conference on Intelligent Transportation Systems (ITSC), IEEE (2018) 3105-3112.

[10] S. Marisamynathan, P. Vedagiri, Modeling pedestrian level of service at signalized intersection under mixed traffic conditions, Transportation research record 2634 (2017) 86-94.

[11] G. Ren, Z. Zhou, W. Wang, Y. Zhang, W. Wang, Crossing behaviors of pedestrians at signalized intersections: observational study and survey in China. Transportation research record 2264 (2011) 65-73.

[12] C. H. Basch, D. Ethan, P. Zybert, C. E. Basch, Pedestrian behavior at five dangerous and busy Manhattan intersections. Journal of community health 40 (2015) 789-792.

[13] W. Daamen, S. P. Hoogendoorn, Experimental research of pedestrian walking behavior. Transportation research record 1828 (2003) 20-30.
[14] M. Twarogowska, P. Goatin, R. Duvigneau, Comparative study of macroscopic pedestrian models. Transportation Research Procedia 2 (2014) 477-485.

[15] P. Das, M. Parida, V. Katiyar, Analysis of interrelationship between pedestrian flow parameters using artificial neural network. Journal of Modern Transportation 23 (2015) 298-309.

[16] C. Chai, X. Shi, Y. D. Wong, M. J. Er, E. T. M. Gwee, Fuzzy logic-based observation and evaluation of pedestrians' behavioral patterns by age and gender. Transportation research part F: traffic psychology and behaviour 40 (2016) 104-118.

[17] X. Song, D. Han, J. Sun, Z. Zhang, A data-driven neural network approach to simulate pedestrian movement. Physica A: Statistical Mechanics and its Applications 509 (2018) 827-844.

[18] X. Yang, X. Yang, Q. Wang, Pedestrian evacuation under guides in a multiple-exit room via the fuzzy logic method. Communications in Nonlinear Science and Numerical Simulation 83 (2020) 105138.

[19] S. M. Hosseinian, I. Bargegol, V. N. Moghaddam Gilani, M. Nikookar, Alireza Orouei, Presentation of regression analysis, GP and GMDH models to predict the pedestrian density in various urban facilities. Front. Struct. Civ. Eng. (2021).

[20] V. N. M. Gilani, M. Sashurpour, S. Hassanjani, S. M. Hosseinian, Analysis of the Effect of the Speed Factor on Highway Safety Using the Machine Learning Method. Slovak Journal of Civil Engineering 29 (2021) 19-28.

[21] V. Najafi Moghaddam Gilani, S. M. Hosseinian, M. Ghasedi, M. Nikookar, Data-driven urban traffic accident analysis and prediction using logit and machine learning-based pattern recognition models, Mathematical problems in engineering (2021).

[22] S. M. Hosseinian, V. Najafi Moghaddam Gilani, H. Tahmasbi Amoli, M. Nikookar, A. Orouei, Presentation of analytical methods for better decision making about the most important factor influencing rural accidents. Mathematical Problems in Engineering 2021 (2021)

[23] H. Ziari, H. Divandari, S. M. Seyed Ali Akbar, S. M. Hosseinian, Investigation of the effect of crumb rubber powder and warm additives on moisture resistance of SMA mixtures. Advances in Civil Engineering 2021 (2021)

[24] H. Hariri Asli, M. Arabani, Y. Golpour, Reclaimed Asphalt Pavement Based on a Geospatial Information System, Slovak Journal of Civil Engineering 28 (2020) 36-42.

[25] V. N. M. Gilani, S. M. Hosseinian, G. H. Hamedi, D. Safari, Presentation of predictive models for two-objective optimization of moisture and fatigue damages caused by deicers in asphalt mixtures. Journal of Testing and Evaluation 49 (2021)

[26] V. N. M. Gilani, S. M. Hosseinian, M. Nikookar, Presentation of a new deicer with the least moisture and fatigue failures in asphalt mixtures. Arabian Journal for Science and Engineering (2021) 1-15.

[27] A. G. Mahani, P. Bazoobandi, S. M. Hosseinian, H. Ziari, Experimental investigation and multi-objective optimization of fracture properties of asphalt mixtures containing nano-calcium carbonate. Construction and Building Materials 285 (2021) 122876.

[28] V. N. M. Gilani, S. M. Hosseinian, H. Behbahani, G. H. Hamedi, Prediction and pareto-based multi-objective optimization of moisture and fatigue damages of asphalt mixtures modified with nano hydrated lime. Construction and Building Materials 261 (2020) 120509. 